Bond University

Research Repository

\title{
Endurance Sports
}

\section{Cox, Gregory Roland}

\section{Published in:}

Nutrition for Sport, Exercise and Performance: A practical guide for students, sports enthusiasts and professionals

DOI:

10.4324/9781003116592-17

\section{Licence:}

Other

Link to output in Bond University research repository.

Recommended citation(APA):

Cox, G. R. (2019). Endurance Sports. In R. Belski, A. Forsyth, \& E. Mantzioris (Eds.), Nutrition for Sport, Exercise and Performance: A practical guide for students, sports enthusiasts and professionals (pp. 188-207). Routledge. https://doi.org/10.4324/9781003116592-17

\section{General rights}

Copyright and moral rights for the publications made accessible in the public portal are retained by the authors and/or other copyright owners and it is a condition of accessing publications that users recognise and abide by the legal requirements associated with these rights.

For more information, or if you believe that this document breaches copyright, please contact the Bond University research repository coordinator. 


\title{
Chapter 13
}

\section{Nutrition for Endurance Sports}

\author{
Gregory Cox PhD APD FSDA
}

\section{Sports Nutrition}

\section{Australian Institute of Sport}

\section{7}

\section{greg.cox@ausport.gov.au}

\section{Introduction}

Endurance sport encompasses a variety of activities (i.e. running, swimming, cycling, paddling), sometimes in combination (i.e. adventure racing, triathlon) across a range of distances and intensities (i.e. $5 \mathrm{~km}$ ocean swim or $10 \mathrm{~km}$ run to an ironman triathlon or a multi-day stage cycling race). While not considered endurance sports by definition as the actual competition only lasts 3-6 minutes (i.e. sprint canoe, rowing, middle distance running), these sports routinely incorporate endurance training sessions. We now acknowledge that endurance sport athletes have unique requirements to maximise favourable responses to training, assist recovery, maintain health and well-being and facilitate daily training and competition performance. Given the requirements to manage body composition, while meeting high daily energy and nutrient demands, purposeful dietary planning is required for endurance athletes.

Understanding the sport culture, the individual athletes' food preferences and beliefs, the dynamics of weekly training, the environmental conditions in which they train and race as well as the logistics for nutrition support will define the effectiveness of nutrition support to endurance sport athletes. This chapter will explore daily training needs of endurance sport athletes and outline various nutrition considerations for endurance competition.

\section{Learning outcomes}

Upon completion of this chapter you will be able to:

1. Understand the nutrition challenges faced by endurance athletes in daily training.

2. Describe daily carbohydrate requirements for endurance athletes and identify important considerations when managing individual athletes.

3. Assess an athlete's daily food and fluid intake and identify key areas to modify to 
optimize daily training performance, recovery and the favoured metabolic adaptations to training.

4. Identify important considerations for racing and the need to customise nutrition support across the wide variety of endurance events.

5. Manipulate fluid intake advice according to an athletes' likely requirements.

\section{Nutrition principles for daily training}

Endurance athletes (recreational and elite) commit considerable effort, time and finances into training and racing. Yet, few invest in the services of experienced qualified sports nutrition professionals to assist them in individualising their daily food and fluid intakes or in developing a race nutrition plan. Rather, endurance athletes rely heavily on information from other athletes, online forums, sport specific magazines, supplement company websites and coaches. A common mistake for recreational endurance athletes is to model their daily and/or race nutrition choices off an elite athlete. Social media is commonly used by endurance athletes to inform the broader community about their food and fluid preferences. Daily training, physiology and annual race calendars vary considerably between athletes, which ultimately dictate daily nutritional needs and race-day nutrition tactics. Given the delicate balance to maintain health and well-being, while optimising daily training performance and recovery, expert nutrition advice should be sought by endurance athletes.

Elite and recreational endurance athletes alike, are time poor. Elite endurance athletes can train up to five sessions daily while juggling sponsor commitments, travel and performance support appointments. Recreational endurance athletes, while not training at the same level, are required to balance lifestyle commitments such as work, study and family in between daily workouts. Careful planning of daily meals and snacks which provide nutritious options aligned to the training goals while offering convenience and taste are high priority for endurance athletes. Further, consideration of the annual training plan is required as the emphasis changes throughout the year (see chapter (8 - periodization)).

\section{Matching Daily Energy Needs}

Dietary surveys of endurance athletes commonly report dietary intakes that fall below recommendations for energy (kilojoules), carbohydrate and various vitamins and minerals. This mismatch of daily energy intake to meet the daily energy requirements for training is likely due to a combination of issues. Firstly, there is no strong biological drive to match energy intake to activity-induced energy expenditure. Hunger is often suppressed in endurance athletes following intense training, particularly in activities such as running which can cause gastrointestinal discomfort and upset. Secondly, given the importance of maintaining a light and lean physique to optimise endurance performance, many endurance athletes adopt an overly restrictive approach with their food and fluid choices in an attempt to minimise body fat levels. And lastly, athletes may not be sufficiently organised to ensure appropriate foods and fluids are available on 
heavy training days, creating a practical barrier to meeting their daily energy needs. Interestingly, when athletes are well supported and organised such as athletes contesting the Tour De France - research has demonstrated that athletes are able to match energy intake with daily energy expenditure even on the most strenuous of cycling stages (Saris et al. 1989).

Given daily fluctuations in training, endurance athletes should be educated appropriately to possess the necessary food knowledge and skills to customise daily food and fluid intakes in order to manipulate daily energy, and subsequent nutrient, intakes. Athletes should be well organised to include additional extras in the way of training food and fluids, mid meal snacks and/or main meal extras on heavy training days to increase their daily energy intake. When additional foods and fluids are included throughout the day should be determined by the primary goal of individual training sessions, the time for recovery between training, food and fluid tolerance as well as logistics. Conversely, on rest days or lighter training days when daily energy requirements are reduced, food and fluids intakes should be adjusted accordingly.

Endurance athletes, males and females, are at increased risk of suffering from low energy availability. This is not surprising given the high daily training loads common to many endurance training programs, coupled with an emphasis of maintaining lean physiques. Low energy availability occurs with a reduction in energy intake and/or an increased exercise load, leading to the disruption of hormonal and metabolic systems. Low energy availability is central to RED-S, relative energy deficiency in sport, which affects numerous aspects of health and performance including metabolic rate, menstrual function, bone health, immunity, protein synthesis, cardiovascular and psychological health.

Disordered eating is common in cases of low energy availability, however mismanaged attempts to quickly reduce body mass or fat mass or acute increases in daily training loads may result in low energy availability. Performance support staff and coaches should communicate regularly to discuss the health and well-being of the athletes in their care. Communication around the annual plan and weekly training load is central and allows the sports nutrition professional to adjust messaging around daily fuel requirements. The inclusion of assessment tools such as resting energy expenditure, dietary intake, hormone profiling, body composition and bone health are useful tools in managing endurance athletes to better understand their health and wellbeing.

\section{Carbohydrate intake guidelines for daily training}

For endurance athletes training strenuously, daily carbohydrate demands can exceed the body's capacity to store carbohydrate. Thus, the availability of carbohydrate as fuel to support training performance and assist recovery is crucial. During intense sustained or intermittent exercise typical of endurance events or high intensity endurance 
training sessions, carbohydrate is the primary fuel to support exercise performance. Carbohydrate intake should be modified in response to fluctuations in daily training load. Further, the intake of additional carbohydrate should be strategically coordinated around training to optimize training performance, facilitate recovery and enhance the adaptation to training.

The International Olympic Committee on Nutrition for Sport updated the carbohydrate intake guidelines in 2010 - see Table 1 for an adapted version. This update provided the impetus for sports nutrition professionals to interrogate the guidelines, understand daily training patterns and subsequently customize carbohydrate intake recommendations for individual athletes on a daily basis. No longer are carbohydrate guidelines provided generically to athletes based on body size or type of sport. To tailor daily carbohydrate needs when managing endurance athletes, consider:

- Daily training intensity, frequency and duration.

- Body weight and composition of the athlete.

- Body composition adjustments, whether it be weight loss or additional requirements associated with growth.

- Subjective feedback from the athlete relating to training performance and recovery.

- Gender.

- Training state and training age.

- Changes in the training environment such as altitude and heat.

Insert Table 1

Figure 1 provides a meal plan example for an elite female triathlete. The meal plan highlights the importance of considering the broader nutritional goals of the athlete when planning daily carbohydrate intake. Specific attention should be given to the timing of carbohydrate and use of different carbohydrate foods and fluid to coordinate carbohydrate intake around training to support daily performance and recovery.

Insert Figure 1

How aggressive refueling strategies are employed after exercise should reflect the glycogen likely to have been used in the session, the timing of the next session, the broader nutrition goals of the athlete and next meal time. Hence, the approach taken to refueling strategies should be periodised throughout the week, or even the training year pending the key training goals. A well-thought timetable will allow preparation before, and recovery after, key training sessions and competition. It may not matter that lower intensity sessions are undertaken without full refueling - in fact, there may actually be some advantages to this (see below). 
How much glycogen do endurance athletes use?

An intense high quality endurance cycling session consisting of $8 \times 5$ minute maximal efforts will deplete muscle glycogen stores by about 50 per cent (Stepto et al. 2001). A sports nutrition professional should be familiar with the specific carbohydrate requirements of the athletes they manage when providing advice regarding strategies for carbohydrate intake around daily training and racing.

In the 1-2 hours after hard exercise, the muscle is primed to absorb, and store carbohydrate - hence the window of opportunity. While early feeding promotes refueling at the high end of the storage range, muscle will continue to take up carbohydrate in response to food consumed at meals throughout the day. It is worth taking advantage of this window when recovery time is short and refueling needs are high, but in the case where training is scheduled 24-48 hours later, timing is not particularly important (i.e. in the case after a Friday morning run with the next session scheduled on Sunday morning). The overall carbohydrate intake, not the timing of carbohydrate will be the driving force behind how much muscle glycogen is restored during recovery periods that extend over 24-28 hours.

\section{Training with Low Carbohydrate Availability}

In recent times, much has been written about purposely training and/or sleeping with low muscle glycogen stores to accelerate favourable adaptations that occur in response to aerobic exercise. Training fasted, withholding carbohydrate during extended sessions, limiting carbohydrate during recovery between training sessions, or sleeping with low muscle glycogen stores have been investigated to determine the likely benefits of 'training low'. Whether training low techniques are strategically incorporated into the weekly training schedule should be discussed with the athlete support team as there are several performance and health implications to consider.

\section{Protein to promote recovery and gains in lean body mass}

While much of the research focus on endurance athletes has centered on carbohydrate, protein plays a particularly important role for endurance athletes. Increased protein requirements for endurance athletes are typically met as the athlete increases their daily energy intake. However, strategic timing of protein-containing foods and/or fluids immediately after training and/or during extended training sessions can assist in maintaining and/or increasing lean body mass as well as enhancing favourable metabolic responses to endurance exercise. Sports nutrition professionals should be purposeful in their planning by including protein containing foods and fluids immediately following targeted endurance training sessions (see Figure 1). 
Table 1. Daily carbohydrate intake recommendations for endurance athletes (adapted from Burke et al. 2011)

\begin{tabular}{|c|c|c|c|}
\hline & Situation & Carbohydrate targets & Comments on type and timing of carbohydrate intake \\
\hline \multicolumn{4}{|c|}{$\begin{array}{l}\text { DAILY CARBOHYDRATE NEEDS TO SUPPORT TRAINING AND RECOVERY - these general recommendations should be fine-tuned with } \\
\text { individual consideration of total energy needs, body composition, daily training loads and feedback from training performance }\end{array}$} \\
\hline Light & $\begin{array}{l}\text { Low intensity or skill-based } \\
\text { activities }\end{array}$ & $3-5 \mathrm{~g} / \mathrm{kg} / \mathrm{d}$ & \multirow{4}{*}{$\begin{array}{l}\text { Timing of carbohydrate intake around training should support the } \\
\text { primary goal for each session. Convenience, athlete tolerance, individual } \\
\text { preferences and logistics are important considerations. } \\
\text { Nutrient-rich carbohydrate food/fluids assist the athlete to meet overall } \\
\text { nutrition goals and should be prioritised. } \\
\text { Timely intake of a carbohydrate-containing food/fluid immediately post } \\
\text { training should align with overall nutrition goals and consider timing of } \\
\text { next training session and scheduled meal. }\end{array}$} \\
\hline Moderate & $\begin{array}{l}\text { Moderate exercise program (i.e. } \\
1 \mathrm{hr} \text { per day) }\end{array}$ & $5-7 \mathrm{~g} / \mathrm{kg} / \mathrm{d}$ & \\
\hline High & $\begin{array}{l}\text { Endurance program (e.g. } 1-3 \mathrm{~h} / \mathrm{d} \\
\text { mod-high intensity exercise) }\end{array}$ & $6-10 \mathrm{~g} / \mathrm{kg} / \mathrm{d}$ & \\
\hline Very High & $\begin{array}{l}\text { Extreme commitment (i.e. }>4-5 \\
\text { h/d mod-high intensity exercise }\end{array}$ & $8-12 \mathrm{~g} / \mathrm{kg} / \mathrm{d}$ & \\
\hline \multicolumn{4}{|c|}{$\begin{array}{l}\text { ACUTE FUELLING STRATEGIES - these guidelines promote high carbohydrate availability to promote optimal performance in endurance } \\
\text { competition or key training sessions. Event demands and body composition should be considered when interpreting these guidelines. }\end{array}$} \\
\hline $\begin{array}{l}\text { General } \\
\text { fuelling up }\end{array}$ & Endurance events $<90 \mathrm{~min}$ & $5-10 \mathrm{~g} / \mathrm{kg} / \mathrm{d}$ & \multirow{2}{*}{$\begin{array}{l}\text { Athletes may choose compact carbohydrate-rich sources that are low in } \\
\text { fibre/residue and easily consumed to ensure that fuel targets are met } \\
\text { while avoiding issues relating to gastrointestinal discomfort. }\end{array}$} \\
\hline $\begin{array}{l}\text { Carbohydrate } \\
\text { loading }\end{array}$ & Endurance events $>90 \mathrm{~min}$ & $36-48 \mathrm{~h}$ of $8-12 \mathrm{~g} / \mathrm{kg} / \mathrm{d}$ & \\
\hline $\begin{array}{l}\text { Pre-event } \\
\text { fuelling }\end{array}$ & Before exercise ( $>60 \mathrm{~min})$ & $\begin{array}{l}1-4 \mathrm{~g} / \mathrm{kg} \text { consumed } 1-4 \mathrm{hr} \\
\text { before exercise }\end{array}$ & $\begin{array}{l}\text { Timing, amount and type of carbohydrate food and drinks should be } \\
\text { chosen to suit the practical needs of the event and individual } \\
\text { preferences/experiences of the athlete. } \\
\text { Choices high in fat/protein/fibre may need to be avoided to reduce risk of } \\
\text { gastrointestinal issues. } \\
\text { Low glycemic index choices may provide a more sustained source of fuel } \\
\text { for situations where carbohydrate cannot be consumed during exercise, } \\
\text { although being familiar with these foods items are important. } \\
\text { Liquid carbohydrate containing options provide a convenient option, } \\
\text { particularly for athletes unable to tolerate foods due to 'pre-race nerves'. }\end{array}$ \\
\hline
\end{tabular}




\section{Iron is an important micronutrient for endurance athletes}

Endurance athletes are prone to having low iron status caused by inadequate dietary intake in combination with increased iron losses (i.e. through gastrointestinal bleeding, sweating and haemolysis), increased iron needs (i.e. when training at altitude) and reduced iron absorption (which occurs during the post-exercise window, particularly when exercise is undertaken with low glycogen stores). Regardless of the stage of iron depletion, all types of iron deficiency should be carefully managed. A planned assessment schedule for iron status should be considered within the annual training, competition and travel plans of endurance athletes. Athletes will benefit from education that highlights dietary sources of iron as well as ways to improve iron absorption (Table 2). The use of iron supplements may be necessary at specific times for certain athletes and should be managed by the sports medicine physician and sports dietitian.

Table 2. Components in food that affect bioavailability of iron.

\begin{tabular}{|c|c|}
\hline Iron enhancers & Iron inhibitors \\
\hline $\begin{array}{l}\text { Vitamin C-rich foods (ascorbic acid) } \\
\text { - } \quad \text { salad, lightly cooked green } \\
\text { vegetables, some fruits and citrus } \\
\text { fruit juices or vitamin C fortified } \\
\text { fruit juices } \\
\text { Some fermented foods } \\
\text { - } \quad \text { miso, some types of soy sauce } \\
\text { Meat enhancer factor } \\
\text { - } \quad \text { found in beef, liver, lamb, chicken } \\
\text { and fish } \\
\text { Alcohol and some organic acids } \\
\text { - } \quad \text { very low pH foods containing citric } \\
\text { acid, tartaric acid e.g. citrus fruit } \\
\text { Vitamin A and beta carotene } \\
\text { - } \quad \text { liver, animal fats, carrots, sweet } \\
\text { potato }\end{array}$ & $\begin{array}{l}\text { Phytates } \\
\text { - } \text { found in cereal grains, wheat } \\
\text { bran, legumes, nuts, peanut } \\
\text { butter, seeds, bran, soy } \\
\text { products, soy protein and } \\
\text { spinach } \\
\text { Polyphenolic compounds } \\
\text { - } \quad \text { strong tea and coffee, herb tea, } \\
\text { cocoa, red wine, some spices e.g. } \\
\text { oregano } \\
\text { Calcium inhibits both haem and non } \\
\text { haem iron absorption as iron and } \\
\text { calcium co-compete for absorption } \\
\text { across the gut (milk, cheese) } \\
\text { Peptides from partially digested plant } \\
\text { proteins } \\
\text { - } \quad \text { soy protein isolates, soy } \\
\text { products }\end{array}$ \\
\hline
\end{tabular}




\section{Race Day Nutrition Strategies}

Optimal performance during competition is achieved by targeting the factors that would otherwise cause fatigue or a reduction in work output and/or skill. Nutritional factors that can cause fatigue include depletion of glycogen stores, low blood glucose levels (hypoglycaemia), dehydration, low blood sodium levels (hyponatraemia), and gastrointestinal upset. Eating strategies in preparation for the race and during the race should be implemented to avoid or reduce the impact of these problems.

\section{Carbohydrate loading for endurance racing}

Carbohydrate is stored within the muscle as glycogen. Carbohydrate loading, if done appropriately, increases muscle glycogen stores - thereby delaying the point of fatigue, commonly referred to as "bonking" in endurance circles. Carbohydrate loading first came known in the late 1960's when Scandinavian researchers found that 3-4 days of carbohydrate deprivation, followed by 3 days of high carbohydrate eating resulted in a supercompensation of muscle glycogen and a subsequent improvement in endurance exercise capacity (Bergstrom et al. 1967). This method was later refined, when Sherman et al. (1981) found that muscle glycogen stores increased to similar levels without the 3 days of depletion prior to 3-4 days of high carbohydrate eating and rest.

Despite a greater reliance on muscle glycogen when pre-exercise concentrations are elevated with carbohydrate loading prior to exercise, carbohydrate loading is generally associated with enhanced performance when exercise duration exceeds 90 minutes. In shorter duration endurance events i.e. $10 \mathrm{~km}$ road runs, a $40 \mathrm{~km}$ cycling time-trial or a $2-3 \mathrm{~km}$ open water swim, suitable fuel stores in the muscle are achieved by a combination of tapered exercise or rest, plus adequate carbohydrate intake (5-10 $\mathrm{g}$ per kg body mass) over the 24-36 hours before the event. For many athletes, this dietary prescription is already achieved in the everyday training diet, so no extra effort or planning is required. However, for some athletes (often women or athletes on a weight reduction diet) increasing total dietary energy and carbohydrate above their normal intake may be needed to achieve these fueling up goals.

For longer duration events such as marathon, 70.3 or ironman triathlon, achieving a high carbohydrate intake (8-12 g per kg body mass) for 24-72 hours before an event, will require athletes to modify their typical daily food and fluid intake. It is unlikely that an athlete's typical carbohydrate intake will fall within this range to supercompensate muscle glycogen stores. A well-structured and considered carbohydrate loading plan will ensure an athlete increases their carbohydrate intake while avoiding gastrointestinal issues. Table 3 provides some common practice considerations for sports nutrition professionals.

Table 3: Carbohydrate Loading Practice Considerations 
- Athletes should be provided with adequate information regarding the carbohydrate content of foods. Many athletes have limited understanding of the carbohydrate content of everyday foods and fluids as well as formulated supplementary sports foods such as carbohydrate gels, sports drinks and energy bars. Providing a carbohydrate ready reckoner will assist the athlete in achieving required carbohydrate intakes.

- Low fibre foods should be included within a carbohydrate loading plan to help maintain a normal fibre intake for the athlete.

- When devising a carbohydrate loading plan, it's important to understand the athlete's likely exercise routine for the final 2-3 days before competition. Additional training should be considered in dietary planning to ensure adequate energy is available to allow additional carbohydrate consumed to be available for glycogen storage rather than used to meet energy needs.

- When formulating a carbohydrate loading plan, it is important to consider the likely glycogen storage capacity of the athlete when determining the subsequent amount of carbohydrate to be consumed. For well trained, elite athletes who have a long training history and have low-body fat stores, higher amounts of carbohydrate within the guidelines should be considered. For recreationally engaged endurance athletes and those with higher body fat levels, carbohydrate intake goals should be modified to the lower end of suggested intake range.

- If formulating a carbohydrate loading meal plan that includes discretionary foods such as confectionary, soft drink and sports drink, it is worthwhile including a disclaimer such as: The food suggestions and volumes specified in the carbohydrate loading meal plan are specific to carbohydrate loading and should not be misinterpreted to reflect everyday healthy eating habits or strategies. Many of the above suggestions are counter intuitive to everyday healthy eating guidelines and are specific to pre-race endurance competition nutrition requirements.

\section{Pre-race Meal}

A carbohydrate-rich meal or snack scheduled 1-4 hours before a race has a role in fine-tuning competition preparation by topping-up muscle glycogen stores and restoring liver glycogen stores (following an overnight fast). Including fluid $(\sim 400-600 \mathrm{~mL})$ with the pre-exercise meal will maximise fluid retention and ensure the athlete is well-hydrated, especially where a fluid deficit is likely to occur during the event. The pre-race meal should be carbohydrate focused, relatively low in fat, contain moderate amounts of protein. Above all, the pre-race meal should be familiar to the athlete to achieve gut comfort throughout the event; neither letting the athlete become hungry nor suffer gastrointestinal distress or upset. Liquid meal alternatives that contain carbohydrate and protein provide an excellent option for athletes that cannot tolerate solid foods immediately before race start. Given the variety of endurance races, scheduling of events, food availability and environmental conditions, athletes are best 
advised to plan and subsequently rehearse their pre-race meal. Fine-tuning may require input from a skilled sports nutrition professional to avoid gastrointestinal upset and optimise the readiness to compete. Table 4 provides some examples of carbohydrate-rich pre-race meals. 
Table 4. Examples of pre-race meals.

Early morning race start. Choices need to be simple and easy to prepare and consume 11/2-2 hours before race start. Water should be included and varied according to anticipated fluid requirements, environmental conditions, other fluids contained within the meal and the athlete's thirst.

- Cooked oats + low-fat milk with honey+ banana + glass of fruit juice

- $3 / 4-1 \frac{1}{2}$ cups of cereal + low-fat milk + slice of toast with savoury spread + milk coffee

- Toasted muffin/s or crumpet/s or bread + jam or honey + banana with 400$600 \mathrm{~mL}$ of sports drink $+1 / 2-1$ sports bar

- 1-2 Pancakes with syrup + liquid meal replacement

- 400-600 mL of sports drink + sports bar

- Fruit smoothie (banana, low-fat milk, yoghurt and honey) or fruit smoothie

Late race start. Normal schedule of meals should be consumed before the pre-race meal. Timing of pre-race meal can be varied to suit athlete preference (1-3 hours prerace). Water should be included and varied according to anticipated fluid requirements, environmental conditions, other fluids contained within the meal and the athlete's thirst.

- Roll(s) or sandwich(es) + 400-600mL of sports drink

- Spaghetti with tomato or low-fat sauce + glass of fruit juice

- $1 / 2-1$ cup of creamed rice +2 slices of toast with savoury spread and 400-600 $\mathrm{mL}$ of sports drink

\section{Important considerations for carbohydrate intake during racing}

Reported race-day carbohydrate intake rates vary considerably between athletes undertaking endurance exercise. This is not surprising as some events or disciplines within a multi-discipline event provide better access and tolerance to the intake of food and fluids. For example, Kimber et al. (2002) found that 73 per cent of the total energy consumed during an ironman triathlon was consumed during the cycle leg of the race. One interesting finding from this study was that, overall finishing time was inversely related to carbohydrate intake during the run for male competitors. Pfeiffer et al. (2012), also found that high rates of carbohydrate intake were usually observed in faster athletes, however this is associated with increased rates of gastrointestinal upset such as nausea and flatulence. While there are obvious benefits to providing carbohydrate during endurance sports on exercise performance (Stellingwerff and Cox 2014), it's important that carbohydrate intake suggestions are well tolerated by the athlete. Many athletes do not consume carbohydrate routinely during training (Burke et al. 2003), which may partially explain why they suffer from gastrointestinal upset and discomfort when they compete and ingest carbohydrate containing fluids and foods. 
Researchers at the Australian Institute of Sport were the first to demonstrate that athletes are able to increase their use of ingested carbohydrate during a simulated race, if they routinely consume carbohydrate during daily training for 4 weeks (Cox et al. 2010a). It appears that athletes can train their gut to increase absorption and subsequent delivery of the ingested carbohydrate to the working muscle. The practical significance of this research highlights the importance of 'training the way you race'. In preparation for endurance racing, athletes should rehearse their race carbohydrate intake strategies in race-like training sessions that mimic the demands of competition.

The amount, timing, type, frequency of intake and form of carbohydrate should be considered when advising endurance athletes in regards to carbohydrate intake during training and racing (Table 5). In brief, in high intensity endurance sports less than 45 minutes, there appears to be little benefit to consuming carbohydrate during exercise. While the athlete should start exercise with normalised muscle glycogen stores, there is little to gain by consuming carbohydrate in these brief endurance events or training sessions. However, consuming small amounts of carbohydrate, even rinsing the mouth with carbohydrate, provides a performance advantage in endurance exercise lasting 45-75 minutes (Rollo and Williams 2011). Consuming carbohydrate in these events provides a central stimulus, altering the perception of effort and allowing for greater work outputs. The frequency of exposure, not the amount of carbohydrate consumed is central to planning carbohydrate intake strategies for these events.

\section{Insert Table 5}

As the duration of the endurance event extends beyond 90 minutes, providing carbohydrate during exercise will provide an alternate fuel for the exercising muscle while maintaining high rates of carbohydrate oxidation. Furthermore, carbohydrate intake will assist in maintaining blood glucose levels within normal ranges. For extended duration endurance events there is a dose response benefit to consuming carbohydrate (Smith et al. 2013). The maximal amount tolerated and available for oxidation will be increased by consuming multiple transportable carbohydrates (glucose and fructose) as they are absorbed across the gut on different transporters. Further, as previously mentioned rehearsing race-day carbohydrate intakes, particularly high rates of carbohydrate, will improve tolerance.

There is a myriad of sports foods, fluids and everyday food items that can be incorporated into a race day plan for an endurance athlete. The combination of everyday food items and use of specialised sports foods should be based on the ease of intake and the athlete's food and fluid preferences. Table 6 provides various suggestions for race day food and fluid intakes.

\section{Insert Table 6}


Table 5. Carbohydrate intake recommendations for endurance athletes during exercise (adapted from Burke et al. 2011)

\begin{tabular}{|c|c|c|c|}
\hline & Situation & Carbohydrate targets & Comments on type and timing of carbohydrate intake \\
\hline $\begin{array}{l}\text { During brief } \\
\text { exercise }\end{array}$ & $\begin{array}{l}<45 \mathrm{~min} \text { (e.g. } 10 \mathrm{~km} \text { track } \\
\text { event) }\end{array}$ & Not needed & \\
\hline $\begin{array}{l}\text { During sustained } \\
\text { high intensity } \\
\text { training sessions } \\
\text { or races }\end{array}$ & $\begin{array}{l}45-75 \text { min (e.g. half marathon, } \\
\text { road cycling time trial) }\end{array}$ & $\begin{array}{l}\text { Small amounts including } \\
\text { mouth rinse }\end{array}$ & $\begin{array}{l}\text { Carbohydrate containing drinks including sports drinks and } \\
\text { carbohydrate gels provide practical options for athletes } \\
\text { undertaking high intensity endurance sports. }\end{array}$ \\
\hline $\begin{array}{l}\text { During endurance } \\
\text { events or } \\
\text { extended training } \\
\text { sessions }\end{array}$ & 1-2.5 h (e.g. marathon) & $30-60 \mathrm{~g} / \mathrm{h}$ & $\begin{array}{l}\text { Most endurance events require athletes to refuel/rehydrate } \\
\text { while they are actually racing. The availability of foods and } \\
\text { fluids varies according to the race. Race organisers may } \\
\text { provide selected foods and fluids from feed/aid stations on } \\
\text { the course. Whereas some athletes may carry their own } \\
\text { supplies. } \\
\text { A range of everyday foods/fluids and specialised sports } \\
\text { supplements ranging from sports drinks and gels provide } \\
\text { convenient, well tolerated options. } \\
\text { Athletes should practice in training to find a refuelling plan } \\
\text { that suits their individual goals including hydration needs } \\
\text { and gut comfort. }\end{array}$ \\
\hline $\begin{array}{l}\text { During ultra- } \\
\text { endurance } \\
\text { exercise }\end{array}$ & $\begin{array}{l}>2.5-3 \text { h (e.g. ultramarathons, } \\
\text { Ironman triathlons, cycling } \\
\text { stage races) }\end{array}$ & Up to $90 \mathrm{~g} / \mathrm{h}$ & $\begin{array}{l}\text { As above. } \\
\text { Higher intakes of carbohydrate are associated with better } \\
\text { performance. } \\
\text { Specifically designed sports foods and fluids providing } \\
\text { multiple transportable carbohydrates (glucose:fructose } \\
\text { mixtures) will achieve high rates of oxidation of } \\
\text { carbohydrate consumed during exercise. }\end{array}$ \\
\hline
\end{tabular}




\begin{tabular}{|l|l|l|l|}
\hline & Situation & Carbohydrate targets & Comments on type and timing of carbohydrate intake \\
\hline & & & $\begin{array}{l}\text { Including a variety of tastes and textures during longer or } \\
\text { multi-day endurance races is important to avoid 'flavour } \\
\text { fatigue'. }\end{array}$ \\
\hline
\end{tabular}


Table 6. Carbohydrate food and fluid suggestions for endurance racing

\section{High-intensity endurance events 45-75 min.}

- Small quantities (exposures) of carbohydrate.

- Mouth rinse or frequent intake of carbohydrate containing drinks (i.e. sports drink) if practical and tolerated + water as tolerated.

\section{High-intensity endurance events 90-150 min.}

- Carbohydrate intake target of 30-60 g of carbohydrate/h.

- Water should be consumed to thirst in addition to carbohydrate containing fluid listed to top-up fluid intake.

\section{Hourly Suggestions:}

- 200-300 mL of sports drink \pm sports gel (25-30 g CHO per gel) OR

- $\quad$ 200-300 mL of cola soft drink \pm sports gel (25-30 g CHO per gel) OR

- 400-600mL of sports drink OR

- 1-2 x sports gel (25-30 g CHO per gel)

Endurance events $>21 / 2-3 \mathrm{~h}$.

- Carbohydrate intake target is up to $90 \mathrm{~g}$ of carbohydrate/h.

- For ultra-endurance races a variety of tastes (sweet and savoury) should be included to avoid flavour fatigue.

- The amount of carbohydrate consumed should reflect the nature of the event and specific requirements of the athlete.

- The combination of solid versus liquid forms of carbohydrate should be modified to reflect the intensity of exercise and the duration of the event.

- Intake of carbohydrate containing fluids should be managed to control hourly carbohydrate intake.

- Water should be consumed to thirst in addition to carbohydrate containing fluid listed to top-up fluid intake.

\section{Hourly carbohydrate suggestions for $40-60 \mathrm{~g} / \mathrm{h}$}

- 300-400 mL of sports drink + 1 x sport gel (25-30 g CHO per gel) OR

- 2 x sport gels (25-30 g CHO per gel) OR

- 400-600 mL of sports drink + banana OR

- $600 \mathrm{~mL}$ of sports drink + nut muesli bar OR

- 400-500 mL of cola drink 


\section{Hourly carbohydrate suggestions for $70-90 \mathrm{~g} / \mathrm{h}$}

- $600 \mathrm{~mL}$ of sports drink +2 x sport gels (25-30 g CHO per gel) OR

- 500-600 mL of sports drink + sandwich (savoury or sweet spread) OR

- $200 \mathrm{~mL}$ of sports gel concentrate - 8 x sports gels ( $\sim 25 \mathrm{~g} \mathrm{CHO}$ per gel) added to a $600 \mathrm{~mL}$ drink bottle topped up with water to $600 \mathrm{~mL} \mathrm{OR}$

- $600 \mathrm{~mL}$ of cola drink + 1/2 sports bar (40 g CHO per bar) OR

- $250 \mathrm{~mL}$ of liquid meal supplement + cereal bar or granola bar OR

- 400-600 mL of sweetened iced tea $+40 \mathrm{~g}$ of dried fruit and nut mix $+1 / 2-1$ sandwich (savoury spread) OR

- 300-500 mL of sports drink +60 g chocolate bar +20 g packet of crisps OR

- $40 \mathrm{~g}$ of confectionery or sports confectionery +2 pikelets and jam + fun size chocolate bar 


\section{Fluid intake considerations for endurance athletes}

In many endurance sports, sweat losses are considerable, resulting in significant loss of fluid and dehydration. This is magnified in hot, humid environments and in sports where there are practical barriers to drinking (i.e. mountain bike racing, marathon running). Earlier laboratory studies consistently reported that the stress associated with exercise increased in response to the level of fluid deficit. However, there is some controversy regarding the effect of dehydration on endurance exercise performance particularly in field settings (Goulet 2012). The point at which the effects become apparent depend on the individual, their level of training and fitness, their starting hydration status, their acclimation and the environment (effects are greater in the heat or at altitude).

Race and or training fluid intake advice should be individualised to ensure athletes use available opportunities to drink fluids at a rate that prevents thirst, and keeps their accumulating fluid deficit below $2 \%$ of body mass. Figure 2 provides an insight into the complex nature of providing individualised fluid intake advice. For instance, an elite male triathlete racing at high speeds in a hot Olympic distance triathlon should create opportunities to maximise fluid intake, and take visual cues from other athletes as a reminder to drink as sweat losses will be high and opportunities to drink limited. Further, the speed of racing will impact on tolerance and gut comfort when ingesting fluids. By contrast, a recreational female runner who runs/walks a marathon in cool weather can expect lower sweat rates, while having ample opportunity to slow or stop at aid stations. For this athlete, controlling her opportunities, rather than drinking as much as tolerated, should underpin her fluid intake advice to minimise the risk of over drinking. While not common, overzealous fluid intake combined with low sweat losses may lead to the potentially fatal condition of hyponatremia (low blood sodium concentration; often known as water intoxication). The development of a race fluid intake plan can be assisted by undertaking fluid balance assessments during race-like training sessions in similar environmental conditions so that the athlete can gauge their typical sweat rates in comparison to their opportunity/ability to rehydrate.

Insert Figure 2 (Burke and Cox 2010)

The most suitable drink choices and delivery methods will depend on the sport and the need to address other nutritional goals. Fluids need to be palatable (temperature, taste) and available to encourage intake. Other characteristics to consider include the beverage temperature, which can be manipulated both to improve palatability in the specific environment and to contribute to body temperature regulation; cold fluids and ice slushies can reduce core temperature in hot conditions while warm fluids may increase body temperature in cold environments. Many endurance events offer a range of fluids, most commonly, water, sports drink, cola soft 
drinks and in extended races warm broths or soups. Sports drinks are formulated to meet a range of needs and simultaneously provide fluid, electrolytes and carbohydrate. Cola soft drinks provide additional carbohydrate and small amounts of caffeine which when included in the later third of exercise may provide a performance benefit (Cox et al. 2002). Above all, athletes should be familiar with the sports drink on offer at the endurance event and/or plan to provide their preferred choice.

\section{Summary and key messages}

After reading this chapter, you should be familiar with the training and competition demands of endurance athletes. You should understand the carbohydrate requirements associated with different event durations and intensities, and be able to tailor a nutrition plan based on these requirements with consideration of the individual athlete and environmental conditions.

Key messages:

- In planning daily energy and carbohydrate intakes, it's critical to understand the daily training schedule and purpose of training sessions to optimize training performance, facilitate recovery and promote favourable adaptations to training.

- Well selected, protein containing foods and fluids during recovery post-exercise will optimise recovery and promote gains in lean body mass.

- Endurance athletes commonly suffer from low iron status and as such should be carefully monitored and managed.

- Carbohydrate loading offers particular advantage to endurance athletes competing in events longer than 90 minutes. Dietary strategies should be employed to achieve high carbohydrate intakes while avoiding high intakes of fibre.

- The pre-race meal should be carbohydrate focused and customized to suit the athlete and race schedule. Above all, food and fluids should be familiar to the athlete.

- Carbohydrate intake for racing should be scaled according to the duration and intensity of the event. For athletes consuming high rates of carbohydrate, race day nutrition plans should be rehearsed to minimize the risk of gastrointestinal discomfort during the race.

- Carbohydrate and fluid race-day intakes should be adjusted to suit individual athlete preferences. Given the variety of endurance events, sports nutrition professionals should become familiar with the practical challenges faced by athletes in meeting their race day nutrition goals. 


\section{Test your knowledge}

\section{Study questions}




\section{References}

Bergstrom, J., Hermansen, L., Hultman, E. \& Saltin, B. 1967. Diet, muscle glycogen and physical performance. Acta Physiologica Scandinavia 71: 140-50.

Burke, L. M. \& Cox, G. R. 2010. The complete guide to food for sports performance. Peak nutrition for your sport., Crows Nest, Australia, Allen \& Unwin.

Burke, L. M., Hawley, J. A., Wong, S. H. \& Jeukendrup, A. E. 2011. Carbohydrates for training and competition. Journal of Sports Science 29: Suppl 1, S17-27.

Burke, L. M., Slater, G., Broad, E. M., Haukka, J., Modulon, S. \& Hopkins, W. G. 2003. Eating patterns and meal frequency of elite Australian athletes. International Journal Sport Nutrition and Exercise Metabolism 13: 521-38.

Cox, G. R., Clark, S. A., Cox, A. J., Halson, S. L., Hargreaves, M., Hawley, J. A., Jeacocke, N., Snow, R. J., Yeo, W. K. \& Burke, L. M. 2010. Daily training with high carbohydrate availability increases exogenous carbohydrate oxidation during endurance cycling. Journal of Applied Physiology 109: 126-34.

Cox, G. R., Desbrow, B., Montgomery, P. G., Anderson, M. E., Bruce, C. R., Macrides, T. A., Martin, D. T., Moquin, A., Roberts, A., Hawley, J. A. \& Burke, L. M. 2002. Effect of different protocols of caffeine intake on metabolism and endurance performance. Journal of Applied Physiology 93: 990-9.

Cox, G. R., Snow, R. J. \& Burke, L. M. 2010b. Race-day carbohydrate intakes of elite triathletes contesting olympic-distance triathlon events. International Journal Sport Nutrition and Exercise Metabolism 20: 299-306.

Goulet, E. D. 2012. Dehydration and endurance performance in competitive athletes. Nutrition Reviews 70: S132-6.

Kimber, N. E., Ross, J. J., Mason, S. L. \& Speedy, D. B. 2002. Energy balance during an ironman triathlon in male and female triathletes. International Journal Sport Nutrition and Exercise Metabolism 12: 47-62.

Pfeiffer, B., Stellingwerff, T., Hodgson, A. B., Randell, R., Pottgen, K., Res, P. \& Jeukendrup, A. E. 2012. Nutritional intake and gastrointestinal problems during competitive endurance events. Medicine \& Science in Sports \& Exercise 44: 344-51.

Rollo, I. \& Williams, C. 2011. Effect of mouth-rinsing carbohydrate solutions on endurance performance. Sports Medicine 41: 449-61.

Saris, W. H., Van Erp-Baart, M. A., Brouns, F., Westerterp, K. R. \& Ten Hoor, F. 1989. Study on food intake and energy expenditure during extreme sustained exercise: the Tour de France. International Journal of Sports Medicine 10: S26-31.

Sherman, W. M., Costill, D. L., Fink, W. J. \& Miller, J. M. 1981. Effect of exercise-diet manipulation on muscle glycogen and its subsequent utilization during performance. International Journal of Sports Medicine 2: 114-8.

Smith, J. W., Pascoe, D. D., Passe, D. H., Ruby, B. C., Stewart, L. K., Baker, L. B. \& Zachwieja, J. J. 2013. Curvilinear dose-response relationship of carbohydrate (0-120 g.h(-1)) and performance. Medicine \& Science in Sports \& Exercise 45: 336-41.

Stellingwerff, T. \& Cox, G. R. 2014. Systematic review: Carbohydrate supplementation on exercise performance or capacity of varying durations. Applied, Physiology, Nutrition and Metabolism 39: 998-1011.

Stepto, N. K., Martin, D. T., Fallon, K. E. \& Hawley, J. A. 2001. Metabolic demands of intense aerobic interval training in competitive cyclists. Medicine \& Science in Sports \& Exercise 33: 303-10. 


\section{Additional Reading:}

Mujika, I. 2012. Endurance Training - Science and Practice. Victoria-Gasteiz, Basque Country, Inigo Mujika.

This book is focused on the broader issues of endurance sport providing a detailed overview of the physiological components to performance for training and competition.

Burke, L.M. 2007. Practical Sports Nutrition. Champaign, USA, Human Kinetics.

This book provides a detailed account of + the practical nutrition challenges across a multitude of sports, including endurance sports. 